\title{
Solvent Effects in Acid-Catalyzed Biomass Conversion Reactions**
}

\author{
Max A. Mellmer, Canan Sener, Jean Marcel R. Gallo, Jeremy S. Luterbacher, \\ David Martin Alonso, and James A. Dumesic*
}

\begin{abstract}
Reaction kinetics were studied to quantify the effects of polar aprotic organic solvents on the acid-catalyzed conversion of xylose into furfural. A solvent of particular importance is $\gamma$-valerolactone (GVL), which leads to significant increases in reaction rates compared to water in addition to increased product selectivity. GVL has similar effects on the kinetics for the dehydration of 1,2-propanediol to propanal and for the hydrolysis of cellobiose to glucose. Based on results obtained for homogeneous Brønsted acid catalysts that span a range of $p K_{a}$ values, we suggest that an aprotic organic solvent affects the reaction kinetics by changing the stabilization of the acidic proton relative to the protonated transition state. This same behavior is displayed by strong solid Brønsted acid catalysts, such as H-mordenite and H-beta.
\end{abstract}

The use of organic solvents is pervasive in the chemical industry, and recently it has been shown that organic solvents are beneficial in the chemical conversion of lignocellulosic biomass. ${ }^{[1-3]}$ One such solvent is $\gamma$-valerolactone (GVL), which can be produced from biomass and displays significant improvements in reaction performance for biomass conversion reactions compared to conversion in aqueous media, such as increased catalytic activity and higher selectivity to desired reaction products. ${ }^{[2,3]}$ Furthermore, we have reported that the simultaneous conversion of hemicellulose and cellulose can be achieved using GVL as a solvent in a single reactor, eliminating the need for pretreatment and/or separation steps ${ }^{[4]}$ Recently, we have taken advantage of accelerated rates of cellulose and hemicellulose deconstruction in GVL- $\mathrm{H}_{2} \mathrm{O}$ solvent mixtures to develop a processing strategy to produce streams of $\mathrm{C}_{5}$ and $\mathrm{C}_{6}$ sugars (e.g., $130 \mathrm{gL}^{-1}$ ) from

[*] M. A. Mellmer, Dr. C. Sener, Dr. J. M. R. Gallo, Dr. J. S. Luterbacher, Dr. D. M. Alonso, Prof. J. A. Dumesic

Department of Chemical and Biological Engineering

University of Wisconsin-Madison

Madison, WI 53706 (USA)

E-mail: dumesic@engr.wisc.edu

[**] This work was supported in part by the U.S. Department of Energy, Office of Basic Energy Sciences and by the DOE Great Lakes Bioenergy Research Center (http://www.glbrc.org), which is supported by the U.S. Department of Energy, Office of Science, Office of Biological and Environmental Research, through the Cooperative Agreement BER DE-FC02-07ER64494 between The Board of Regents of the University of Wisconsin System and the U.S. Department of Energy. D.M.A. acknowledges financial support from Glucan Biorenewables, LLC, and support was provided by The Scientific and Technological Research Council of Turkey (TUBITAK, postdoctoral fellowship to C.S.). We acknowledge Jake Center for help with experiments, and we thank Professors Brent Shanks and Johannes Lercher for valuable discussions.

$\because$ Sur

Supporting information for this article is available on the WWW under http://dx.doi.org/10.1002/anie.201408359. biomass. ${ }^{[5]}$ Other polar aprotic solvents, such as $\gamma$-lactones and tetrahydrofurans, have also shown comparable benefits to GVL in biomass conversion processes. ${ }^{[3]}$

Herein, we report the effects of GVL and other polar aprotic solvents on acid-catalyzed biomass conversion reactions using acid catalysts that span a range of $\mathrm{p} K_{\mathrm{a}}$ values. The liquid-phase dehydration of xylose to furfural is catalyzed by Brønsted acids and serves as a probe reaction in the present study. We compare the reactivity trends displayed by these homogeneous acid catalysts in the liquid phase with the performance of solid acid catalysts, the latter of which have been shown to span a range of catalytic activities for the gasphase dehydration of methanol. ${ }^{[6]}$

The catalytic conversion of xylose into furfural is accompanied by various degradation reactions, producing undesirable side products through three prominent degradation pathways: 1) xylose degradation, 2) furfural degradation, and 3 ) bimolecular reactions between xylose and furfural. We have thus collected reaction kinetics data for xylose dehydration, furfural degradation, and the combined conversion of xylose in the presence of furfural. The simplified reaction network displayed in Scheme 1 is generally accepted in the

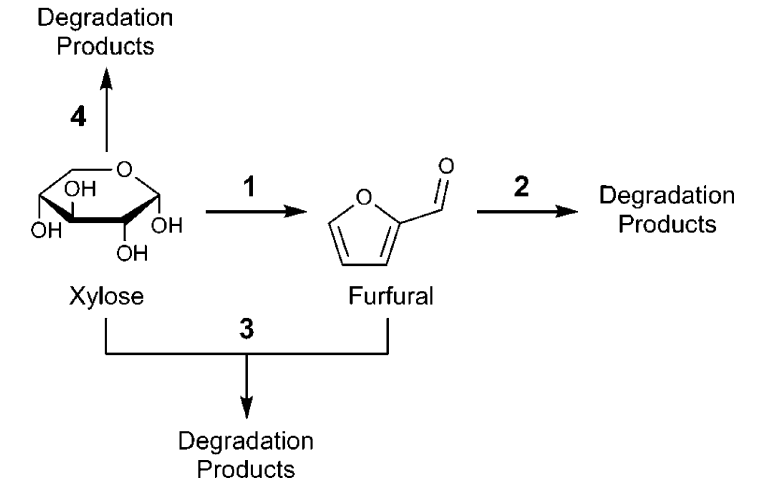

Scheme 1. Reaction network for the acid-catalyzed dehydration of xylose to furfural.

literature to describe the reaction kinetics for xylose conversion into furfural, ${ }^{[7]}$ and we have employed this scheme to calculate kinetic rate constants from our experimental reaction kinetics data.

Values of the rate constants for each pathway of the reaction network in Scheme 1 were determined to quantify the effects of GVL and other aprotic solvents on the reaction rates for various acid catalysts and reaction temperatures. Table 1 shows the turnover frequencies for reaction $1\left(\mathrm{TOF}_{1}\right)$ using homogeneous acid catalysts. With sulfuric acid (SA) as the catalyst, the use of GVL as a solvent increases the $\mathrm{TOF}_{1}$ 
Table 1: Turnover frequencies (TOF) for the dehydration of xylose to furfural (reaction 1) in various solvents for homogeneous Brønsted acid catalysts. ${ }^{[a]}$

\begin{tabular}{llcc}
\hline Solvent $^{[\mathrm{b}]}$ & Catalyst & $T[\mathrm{~K}]$ & TOF $_{1}\left[\mathrm{k} \mathrm{s}^{-1}\right]$ \\
\hline $\mathrm{H}_{2} \mathrm{O}$ & $\mathrm{SA}$ & 448 & $1.5 \pm 0.05$ \\
$\mathrm{GVL}$ & $\mathrm{SA}$ & 448 & $46 \pm 2$ \\
dioxane & $\mathrm{SA}$ & 448 & $21 \pm 1$ \\
$\mathrm{H}_{2} \mathrm{O}$ & $\mathrm{SSA}$ & 448 & $2.6 \pm 0.2$ \\
$\mathrm{GVL}$ & $\mathrm{SSA}$ & 448 & $25 \pm 1$ \\
$\mathrm{H}_{2} \mathrm{O}$ & $\mathrm{SA}$ & 418 & $0.090 \pm 0.01$ \\
$\mathrm{GVL}$ & $\mathrm{SA}$ & 418 & $5.1 \pm 0.2$ \\
THF & $\mathrm{SA}$ & 418 & $1.2 \pm 0.09$ \\
\hline
\end{tabular}

[a] Reaction conditions: xylose $(0.15 \mathrm{M})$, solvent $(4 \mathrm{~mL})$, and stirring at $700 \mathrm{rpm}$. [b] Organic solvents contained $10 \mathrm{wt} \% \mathrm{H}_{2} \mathrm{O}$.

by $30-55$ times compared to the values obtained when $\mathrm{H}_{2} \mathrm{O}$ is used as the solvent. Propylsulfonic acid (PSA), a weaker acid than SA, exhibited a 10 -fold increase in $\mathrm{TOF}_{1}$ for GVL compared to the value in $\mathrm{H}_{2} \mathrm{O}$. Therefore, the reactivity of a homogeneous Brønsted acid catalyst is increased using GVL as solvent, and it appears that this effect is more pronounced for stronger homogeneous acids. More generally, we have found that the high reactivity of a strong Brønsted acid catalyst (i.e., SA) is also observed for other polar aprotic solvents. For example, the results in Table 1 show that polar aprotic solvents such as dioxane and THF also display increased reactivity, similar to GVL.

The apparent activation energies for furfural formation from xylose (reaction 1) and furfural degradation (reaction 2) in $\mathrm{H}_{2} \mathrm{O}$ were determined to be 145 and $85 \mathrm{~kJ} \mathrm{~mol}^{-1}$, respectively, which are in agreement with reported literature values. ${ }^{[8]}$ The use of GVL as a solvent changes the energetics of the reaction network for the conversion of xylose to favor formation of the desired furfural product. The activation energy barrier for xylose dehydration (reaction 1) is decreased in GVL $\left(114 \mathrm{~kJ} \mathrm{~mol}^{-1}\right)$, whereas the barrier for furfural degradation (reaction 2) is higher in GVL $\left(105 \mathrm{~kJ} \mathrm{~mol}^{-1}\right)$. Accordingly, furfural selectivities from xylose of up to $75 \%$ can be achieved in GVL using SA as the catalyst, compared to only $50 \%$ furfural selectivity from xylose in $\mathrm{H}_{2} \mathrm{O}$.

Importantly, we have found that the increased reactivity of a Brønsted acid catalyst in GVL is also observed for other acid-catalyzed reactions, and this behavior is of general significance. For example, the acid-catalyzed dehydration of 1,2-propanediol to propanal displayed an 18-fold reactivity increase using GVL as the solvent compared to the reaction in $\mathrm{H}_{2} \mathrm{O}$. Furthermore, the selectivity for propanal production increased from approximately $60 \%$ in $\mathrm{H}_{2} \mathrm{O}$ to $75 \%$ in GVL. Increases in reactivity were also achieved for a hydrolysis reaction, which is the reverse of a dehydration reaction. The acid-catalyzed hydrolysis of cellobiose to glucose showed a 30-fold reactivity increase using GVL as the solvent compared to the reaction in $\mathrm{H}_{2} \mathrm{O}$. These reactivity and selectivity increases for 1,2-propanediol dehydration and cellobiose hydrolysis are similar to those achieved for xylose dehydration to furfural, and these results show that increased reactivity using GVL as the solvent is not limited to xylose dehydration. Accordingly, this behavior is independent of the specific details of the acid-catalyzed mechanism, suggesting that these solvent effects are related to solvation of the acidicproton catalyst.

We consider that these acid-catalyzed reactions are controlled by two processes, the first of which is the dissociation equilibrium of the acid, $\mathrm{HB}$, into its acidic proton, $\mathrm{H}^{+}$, and its conjugate base, $\mathrm{B}^{-}$:

$\mathrm{HB} \rightleftharpoons \mathrm{H}^{+}+\mathrm{B}^{-}$

In the second process, the acid-catalyzed conversion takes place through a series of steps, one of which is assumed to be the rate-determining step for simplicity. As shown elsewhere, in this case, the overall rate can be written in terms of a product of equilibrium constants for the steps that are not rate-determining, multiplied by the equilibrium constant for the formation of the transition state for the rate-determining step. ${ }^{[9]}$ Accordingly, the overall rate can be expressed in terms of a single equilibrium constant $\left(K_{2}^{\dagger}\right.$, which is a product of the aforementioned individual equilibrium constants) for the formation of the rate-determining transition state from the reactant $R$, as written below:

$\mathrm{R}+\mathrm{H}^{+} \rightleftharpoons \mathrm{RH}^{+}$

The rate of the second process is then given from transition-state theory as:

$r_{2}=\frac{k_{\mathrm{B}} T}{h} K_{2}^{\dagger}[\mathrm{R}]\left[\mathrm{H}^{+}\right]=k_{2}[\mathrm{R}]\left[\mathrm{H}^{+}\right]$

where $k_{\mathrm{B}}$ is the Boltzmann constant, $h$ is Planck's constant, and $k_{2}$ is the overall rate constant for step 2 .

The proton concentration $\left[\mathrm{H}^{+}\right]$can be written in terms of the dissociation constant $K_{1}$ :

$\left[\mathrm{H}^{+}\right]=\frac{-K_{1}+\sqrt{K_{1}^{2}+4 K_{1}\left[\mathrm{HB}_{\mathrm{o}}\right]}}{2}$

where $\mathrm{HB}_{\mathrm{o}}$ is the initial associated-acid concentration. The rate of reaction per unit volume is then given by:

rate $=k_{2}[\mathrm{R}]\left[\mathrm{H}^{+}\right]$

We suggest that the lower reactivity of a Brønsted acid catalyst in water is caused in part by increased solvation of the acidic proton by water molecules. For instance, the standard Gibbs free energy change for solvation of a proton changes from $-1113 \mathrm{~kJ} \mathrm{~mol}^{-1}$ in liquid water to $-1089 \mathrm{~kJ} \mathrm{~mol}^{-1}$ in an aprotic solvent such as acetonitrile. ${ }^{[10]}$ Thus, the proton catalyst is stabilized in water to a greater extent than in an aprotic solvent $\left(\Delta G\left(\mathrm{H}^{+}\right)_{\text {solv }}=24 \mathrm{~kJ} \mathrm{~mol}^{-1}\right.$ for this example), and this proton stabilization would lead to lower reactivity in water, provided that the solvent has a fractional effect $\left(f^{*} \Delta G_{\text {solv }}\left(\mathrm{H}^{+}\right)\right)$on the transition state for the acid-catalyzed reaction relative to stabilization of the reactant, as displayed in Figure 1. Note that the solvent affects the stabilization of both the proton $\left(\mathrm{H}^{+}\right)$and the conjugate base $\left(\mathrm{B}^{-}\right)$, as well as the protonated transition state $\left(\mathrm{RH}^{+\dagger}\right)$. 


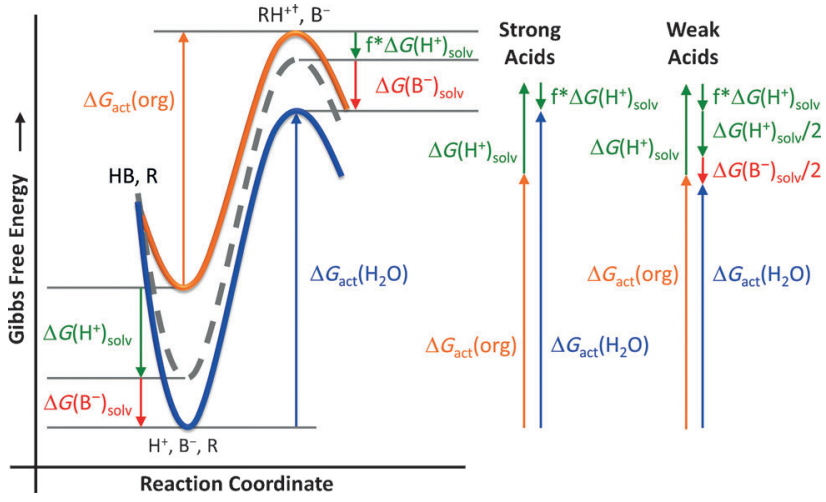

Figure 1. Gibbs free energy surface in $\mathrm{H}_{2} \mathrm{O}$ and polar aprotic organic solvents of the conversion of reactant $\mathrm{R}$ into product $\mathrm{P}$ catalyzed by a Brønsted acid.

According to Figure 1, the reactivity of the proton, as reflected in the value of the rate constant $k_{2}$, is decreased in water owing to stabilization of the proton relative to the protonated transition state for the acid-catalyzed reaction:

$k_{2}=k_{2}^{\mathrm{o}} \exp \left(\frac{+\Delta G\left(\mathrm{H}^{+}\right)_{\text {solv }}\left(1-f^{*}\right)}{R T}\right)$

(The value of $\Delta G\left(\mathrm{H}^{+}\right)_{\text {solv }}$ is negative in moving from an aprotic organic solvent to water.)

An increase in the extent of proton stabilization in water compared to in an aprotic organic solvent affects the acid dissociation constant, thereby altering the number of available acidic protons, which is given by:

$K_{1}=K_{1}^{\mathrm{o}} \exp \left(\frac{-\Delta G\left(\mathrm{H}^{+}\right)_{\mathrm{solv}}-\Delta G\left(\mathrm{~B}^{-}\right)_{\mathrm{solv}}}{R T}\right)$

The aforementioned effects of $\Delta G_{\text {solv }}$ on $k_{2}$ and $K_{1}$ suggest that the effect of solvation on the reaction rate is a function of proton availability $\left(K_{1}\right)$ as well as proton reactivity $\left(k_{2}\right)$. This solvation behavior predicts that the activation free energy $\left(\Delta G_{\text {act }}\right)$ in water is higher than $\Delta G_{\text {act }}$ in aprotic solvents for strong acids, whereas there is only a minimal difference in $\Delta G_{\text {act }}$ using weak acids, as shown by the vector diagram in Figure 1. To test this hypothesis, the TOF values for xylose conversion were determined in $\mathrm{H}_{2} \mathrm{O}$ and GVL using a series of homogeneous acid catalysts (Table 2). In the strong-acid regime (i.e., low pKa values), the TOF for xylose conversion remains constant in a given solvent, showing that the conjugate base of the associated strong Brønsted acid catalyst has little effect on proton reactivity. Table 2 shows a decrease in TOF values in both $\mathrm{H}_{2} \mathrm{O}$ and $\mathrm{GVL}$ at $\mathrm{p} K_{\mathrm{a}}$ values of approximately 0 and -2 , respectively, associated with the decreased proton availability. Finally, Figure 2 shows that the $\mathrm{TOF}_{\mathrm{GVL}} / \mathrm{TOF}_{\mathrm{H}_{2} \mathrm{O}}$ ratio remains constant for strong acids and then decreases for acids having higher $\mathrm{p} K_{\mathrm{a}}$ values. This behavior allows us to describe the increase in reaction rates $\left(\mathrm{TOF}_{\mathrm{GVL}} / \mathrm{TOF}_{\mathrm{H}_{2} \mathrm{O}}\right)$ for acid catalysts of differing strengths in GVL compared to reactions carried out in water (Figure 2).
Table 2: Turnover frequencies (TOF) for xylose conversion in $\mathrm{H}_{2} \mathrm{O}$ and GVL using homogeneous Brønsted acid catalysts with different $\mathrm{p} K_{\mathrm{a}}$

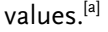

\begin{tabular}{lccc}
\hline \multirow{2}{*}{ Homogeneous acid } & $\mathrm{pK}$ & \multicolumn{2}{c}{$\left.\mathrm{TOF}_{\mathrm{a}} \mathrm{k} \mathrm{s}^{-1}\right]$} \\
& & $\mathrm{H}_{2} \mathrm{O}$ & $\mathrm{GVL}$ \\
\hline triflic acid & -12 & 3.6 & 150 \\
sulfuric acid & -3 & 3.6 & 145 \\
methanesulfonic acid & -1.92 & 3.5 & 34 \\
propylsulfonic acid & -1.53 & 3.7 & 32 \\
trifluoroacetic acid & 0.23 & 3.5 & 3.6 \\
trichloroacetic acid & 0.66 & 1.8 & 2.0 \\
hypophosphorous acid & 1.20 & 1.3 & 1.5 \\
oxalic acid & 1.25 & 1.2 & 0.69 \\
phosphoric acid & 2.15 & 0.61 & 0.69 \\
formic acid & 3.77 & 0.12 & 0.08 \\
acetic acid & 4.76 & 0.042 & 0.033 \\
\hline
\end{tabular}

[a] Reaction conditions: xylose $(0.15 \mathrm{M}), 448 \mathrm{~K}$, solvent $(4 \mathrm{~mL})$, and stirring at $700 \mathrm{rpm}$. [b] GVL contained $10 \mathrm{wt} \% \mathrm{H}_{2} \mathrm{O}$.

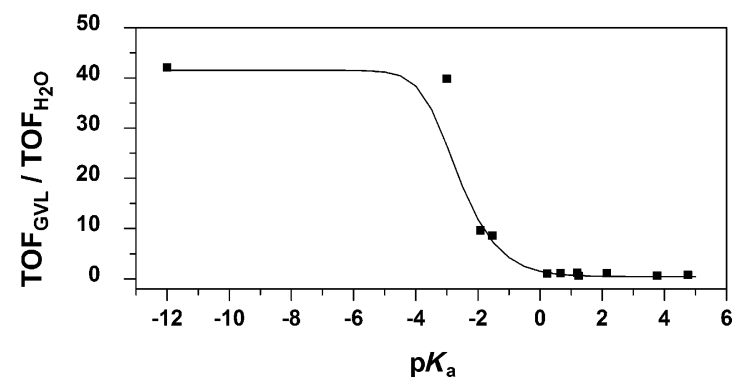

Figure 2. Ratio of the turnover frequencies (TOF) for xylose conversion in $\mathrm{GVL}$ and $\mathrm{H}_{2} \mathrm{O}$ versus the $\mathrm{p} K_{\mathrm{a}}$ value for homogeneous Brønsted acid catalysts. Experimental ( $\mathbf{n})$ and theoretical (-) TOF ratios are given.

Our hypothesis suggests that in the presence of a weak acid (i.e., $K_{1} \rightarrow 0$ ), the reaction rate is given by:

rate $=k_{2}[\mathrm{R}] \sqrt{K_{1}\left[\mathrm{HB}_{\mathrm{o}}\right]}=k[\mathrm{R}]\left[\mathrm{HB}_{\mathrm{o}}\right]^{0.5}$

suggesting that the rate dependence on the acid concentration of a weak acid is of fractional order $1 / 2$. Using the weak acid catalyst phosphoric acid $\left(\mathrm{p} K_{\mathrm{a}} 2.15\right)$, the reaction rate for xylose conversion in $\mathrm{H}_{2} \mathrm{O}$ was confirmed to be of order 0.55 with respect to acid concentration, which is in agreement with our hypothesis.

Having demonstrated that the reactivity of a strong homogeneous Brønsted acid in a liquid solvent is dependent on $\Delta G\left(\mathrm{H}^{+}\right)_{\text {solv }}$ and independent of the nature of the conjugate base, we can now test whether this behavior in the liquid phase is also valid for strong solid Brønsted acid catalysts. The TOF values for solid Brønsted acids are shown in Table 3, and a comparison with the results in Table 1 for strong homogeneous acids shows that the TOF values for supported propylsulfonic acid on silica (SiliaBond PSA), H-mordenite (H-MOR), and H-beta (H-BEA) are of the same order of magnitude as the values for $\mathrm{SA}$ in GVL and $\mathrm{H}_{2} \mathrm{O}$. The supported propylsulfonic acid on silica displays a 19-fold increase in $\mathrm{TOF}_{1}$ using GVL as the solvent compared to the 
Table 3: Turnover frequencies (TOF) for the dehydration of xylose to furfural (reaction 1) in various solvents for heterogeneous acid catalysts and heteropoly acids. ${ }^{[a]}$

\begin{tabular}{lllc}
\hline Solvent $^{[\mathrm{b}]}$ & Catalyst & $T[\mathrm{~K}]$ & TOF $_{1}\left[\mathrm{k} \mathrm{s}^{-1}\right]$ \\
\hline $\mathrm{H}_{2} \mathrm{O}$ & SiliaBond PSA & 448 & $4.9 \pm 0.3$ \\
$\mathrm{GVL}$ & SiliaBond PSA & 448 & $92 \pm 10$ \\
$\mathrm{H}_{2} \mathrm{O}$ & $\mathrm{H}-\mathrm{MOR}$ & 448 & $1.7 \pm 0.1$ \\
$\mathrm{GVL}$ & $\mathrm{H}-\mathrm{MOR}$ & 448 & $9.4 \pm 0.3$ \\
$\mathrm{H}_{2} \mathrm{O}$ & $\mathrm{H}_{4} \mathrm{SiW}_{12} \mathrm{O}_{40}$ & 418 & $0.42 \pm 0.1$ \\
$\mathrm{GVL}$ & $\mathrm{H}_{4} \mathrm{SiW}_{12} \mathrm{O}_{40}$ & 418 & $10 \pm 2$ \\
$\mathrm{H}_{2} \mathrm{O}$ & $\mathrm{H}-\mathrm{BEA}$ & 418 & $0.69 \pm 0.4$ \\
$\mathrm{GVL}$ & $\mathrm{H}-\mathrm{BEA}$ & 418 & $30 \pm 5$ \\
\hline
\end{tabular}

[a] Reaction conditions: xylose $(0.15 \mathrm{M})$, solvent $(4 \mathrm{~mL})$, and stirring at $700 \mathrm{rpm}$. [b] GVL contained $10 \mathrm{wt} \% \mathrm{H}_{2} \mathrm{O}$.

reaction in $\mathrm{H}_{2} \mathrm{O}$, whereas the homogeneous analogue PSA exhibited a 10 -fold increase in $\mathrm{TOF}_{1}$ between the GVL and $\mathrm{H}_{2} \mathrm{O}$ solvent systems, suggesting that the solid acid might be slightly stronger. The H-MOR and H-BEA catalysts displayed 6- and 43-fold increases in the $\mathrm{TOF}_{1}$ values, respectively, between the GVL and $\mathrm{H}_{2} \mathrm{O}$ solvent systems. The large increase in $\mathrm{TOF}_{1}$ in GVL compared to $\mathrm{H}_{2} \mathrm{O}$ using $\mathrm{H}$-BEA suggests that this solid acid is fully deprotonated in the solvent, similar to the behavior of SA. The smaller increase in the value of $\mathrm{TOF}_{1}$ for $\mathrm{H}-\mathrm{MOR}$ suggests that this catalyst might be weaker than H-BEA or suffer from diffusional limitations of xylose and furfural in the 1-dimensional zeolite pore channels. Furthermore, we observed negligible reactivity using H-BEA as the catalyst for the hydrolysis of cellulose (a polymer too large to access the acid sites within the microporous channels), verifying the heterogeneous nature of the xylose dehydration reaction using this solid acid catalyst.

The results of the present study suggest that the reactivity of a strong solid Brønsted acid catalyst in the liquid phase is similar to that of a strong homogeneous Brønsted acid. This reactivity depends on the extent of proton solvation in the solvent, but only little on the nature of the conjugate base. This behavior of a solid Brønsted acid in a liquid solvent is in contrast to its reactivity for a gas-phase reaction. For example, studies of the gas-phase acid-catalyzed dehydration of methanol ${ }^{[6]}$ have shown that the rate constants for dehydration over $\mathrm{H}_{4} \mathrm{SiW}_{12} \mathrm{O}_{40}$ are an order of magnitude larger than those over H-BEA, which is due to the higher deprotonation energy associated with the $\mathrm{H}$-BEA catalyst. In contrast, in our liquid-phase dehydration study, the $\mathrm{TOF}_{1}$ values are of the same order of magnitude for the $\mathrm{H}_{4} \mathrm{SiW}_{12} \mathrm{O}_{40}$ and H-BEA catalysts in both GVL and $\mathrm{H}_{2} \mathrm{O}$ (Table 3), suggesting that the liquid solvent decreases the disparity in deprotonation energies between heterogeneous catalysts owing to solvation of the acidic proton.
In summary, we have studied the effects of polar aprotic solvents, such as GVL, on a variety of acid-catalyzed biomass conversion reactions and compared these solvent effects to reactions performed in water. Significant increases in reaction rates as well as increased product selectivities were observed using GVL as the solvent. We have shown that the use of GVL as the solvent changes the activation energies for the probe reaction, the dehydration of xylose to furfural. We suggest that the polar aprotic solvents studied here affect the stabilization of the acidic proton relative to the protonated transition states, leading to accelerated reaction rates for these acid-catalyzed biomass conversion reactions. These solvent effects were also observed for strong solid Brønsted acid catalysts, suggesting that the protons of these catalysts become solvated during the liquid-phase catalytic reactions.

Received: August 19, 2014

Published online: $\square \square \square \square, \square \square \square$

Keywords: biomass - catalysis - kinetics - solvent effects . sustainable chemistry

[1] a) S. G. Wettstein, D. M. Alonso, E. I. Gürbüz, J. A. Dumesic, Curr. Opin. Chem. Eng. 2012, 1, 218-224; b) C. M. Cai, T. Y. Zhang, R. Kumar, C. E. Wyman, Green Chem. 2013, 15, $3140-$ 3145; c) Y. Gu, F. Jerome, Chem. Soc. Rev. 2013, 42, 9550-9570; d) S. Dutta, S. Pal, Biomass Bioenergy 2014, 62, 182-197.

[2] a) L. Qi, I. T. Horvath, ACS Catal. 2012, 2, 2247-2249; b) D. M. Alonso, J. M. R. Gallo, M. A. Mellmer, S. G. Wettstein, J. A. Dumesic, Catal. Sci. Technol. 2013, 3, 927 -931; c) J. M. R. Gallo, D. M. Alonso, M. A. Mellmer, J. H. Yeap, H. C. Wong, J. A. Dumesic, Top. Catal. 2013, 56, 1775-1781; d) E. I. Gürbüz, J. M. R. Gallo, D. M. Alonso, S. G. Wettstein, W. Y. Lim, J. A. Dumesic, Angew. Chem. Int. Ed. 2013, 52, 1270-1274; Angew. Chem. 2013, 125, 1308-1312; e) L. Zhang, H. Yu, P. Wang, Y. Li, Bioresour. Technol. 2014, 151, 355 -360; f) L. Qi, Y. F. Mui, S. W. Lo, M. Y. Lui, G. R. Akien, I. T. Horvath, ACS Catal. 2014, 4, $1470-1477$

[3] J. M. R. Gallo, D. M. Alonso, M. A. Mellmer, J. A. Dumesic, Green Chem. 2013, 15, 85-90.

[4] D. M. Alonso, S. G. Wettstein, M. A. Mellmer, E. I. Gurbuz, J. A. Dumesic, Energy Environ. Sci. 2013, 6, 76-80.

[5] J. S. Luterbacher, J. M. Rand, D. M. Alonso, J. Han, J. T. Youngquist, C. T. Maravelias, B. F. Pfleger, J. A. Dumesic, Science 2014, 343, 277-280.

[6] R. T. Carr, M. Neurock, E. Iglesia, J. Catal. 2011, 278, 78-93.

[7] B. Danon, G. Marcotullio, W. de Jong, Green Chem. 2014, 16, $39-54$.

[8] a) D. L. Williams, A. P. Dunlop, Ind. Eng. Chem. 1948, 40, 239241; b) D. F. Root, J. F. Saeman, J. F. Harris, W. K. Neill, For. Prod. J. 1959, 9, 158-165.

[9] a) J. A. Dumesic, J. Catal. 1999, 185, 496-505; b) J. A. Dumesic, J. Catal. 2001, 204, 525-529.

[10] C. P. Kelly, C. J. Cramer, D. G. Truhlar, J. Phys. Chem. B 2007, $111,408-422$ 


\section{Communications}

Biomass Conversion

M. A. Mellmer, C. Sener, J. M. R. Gallo, J. S. Luterbacher, D. M. Alonso, J. A. Dumesic* III-IIII

Solvent Effects in Acid-Catalyzed Biomass Conversion Reactions

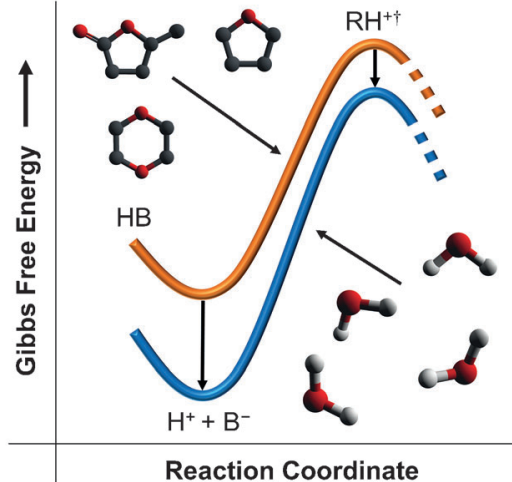

In acid-catalyzed biomass conversion (e.g., dehydration of xylose to furfural), the use of polar aprotic organic solvents, such as $\gamma$-valerolactone, affects the stabilization of the acidic proton relative to the protonated transition states. This leads to accelerated reaction rates and increased product selectivities compared to the transformations in aqueous media. 